\title{
Mutation-Positive Lynch Syndrome
}

National Cancer Institute

\section{Source}

National Cancer Institute. Mutation-Positive Lynch Syndrome. NCI Thesaurus. Code C150715.

A finding of Lynch syndrome in which one is identified as a carrier or obligate carrier of a pathogenic mutation(s) in one of several DNA mismatch repair genes, including MLH1, MSH2/EPCAM, MSH6 or PMS2. 